\title{
Long-Term Survival after Invasive or Conservative Strategy in Elderly Patients with non-ST-Elevation Myocardial Infarction: A Prospective Cohort Study
}

\author{
Kristin Marie Kvakkestad a, b, d Jon Michael Gran ${ }^{c} \quad$ Jan Eritsland ${ }^{a}$ \\ Charlotte Holst Hansen $^{a}$ Eigil Fossum ${ }^{a}$ Geir Øystein Andersen ${ }^{a}$ \\ Sigrun Halvorsen ${ }^{a, b}$ \\ ${ }^{a}$ Department of Cardiology, Oslo University Hospital Ullevål, Oslo, Norway; ${ }^{b}$ Institute of Clinical Medicine, University \\ of Oslo, Oslo, Norway; ${ }^{C}$ Oslo Centre for Biostatistics and Epidemiology, Research Support Services, Oslo University \\ Hospital and University of Oslo, Oslo, Norway; ${ }^{d}$ Department of Medicine, Østfold Hospital, Kalnes, Grålum, Norway
}

\section{Keywords}

Non-ST-segment elevation myocardial infarction · Elderly · Invasive strategy $\cdot$ Long-term survival

\begin{abstract}
Background: The optimal management of elderly patients with non-ST-segment elevation myocardial infarction (NSTEMI) is still discussed. We aimed to study short- and long-term survival in NSTEMI patients $\geq 75$ years managed with an invasive or a conservative strategy. Methods: NSTEMI patients admitted to Oslo University Hospital Ulleval during 2005-2011 were included consecutively in a prospective registry. Vital status until December 31, 2013, was obtained from the Norwegian Cause of Death Registry. Patients $\geq 75$ years were identified, and 30-day and 7-year survival were analyzed. Logistic- and Cox regression was used to estimate OR and hazard ratio (HR) for death in the invasive versus conservative group, adjusting for registered confounders. Results: There were 2,064 NSTEMI patients $\geq 75$ years $(48.2 \%$ women); $1,200(58.1 \%)$ were treated with an invasive strategy, and were younger, more likely to be male and previously revascularized compared to 864 (41.9\%) patients treat-
\end{abstract}

ed conservatively ( $p<0.0001$ for all). Survival at 30-day was $94.9 \%$ in the invasive and $76.6 \%$ in the conservative group. For 30 -day survivors, 7-year survival was $47.4 \%$ ( $95 \% \mathrm{Cl} 42.9-$ 51.8) and $11.6 \%$ (95\% Cl 8.3-15.6), respectively. After multivariate adjustment, an invasive strategy was associated with lower long-term risk (adjusted HR [aHR] 0.49 [95\% Cl 0.410.59]). Actual revascularization was associated with lower risk of long-term mortality compared to angiography only $\left(\mathrm{aHR}_{\mathrm{PCl}} 0.73\right.$ [95\% Cl 0.59-0.90], aHR CABG 0.43 [95\% Cl 0.28$0.65])$. Conclusion: In this real-life cohort of NSTEMI patients $\geq 75$ years, 30 -day survival was $95 \%$, and 7 -year survival was $47 \%$ with an invasive strategy. Revascularized patients had a superior long-term prognosis. With a conservative strategy, short- and long-term survival was lower, probably due to selection bias and unmeasured confounding.

$$
\begin{aligned}
& \text { (c) } 2019 \text { The Author(s) } \\
& \text { Published by S. Karger AG, Basel }
\end{aligned}
$$

\section{Introduction}

Several randomized controlled trials (RCTs) have demonstrated improved outcomes in patients with nonST-segment elevation myocardial infarction (NSTEMI)

\begin{tabular}{ll}
\hline KARGER & The Author(s) \\
& Published by S. Karger AG, Basel \\
E-Mail karger@karger.com & This article is licensed under the Creative Commons Attribution- \\
www.karger.com/crd & $\begin{array}{l}\text { NonCommercial-NoDerivatives 4.0 International License (CC BY- } \\
\text { NC-ND) (http://www.karger.com/Services/OpenAccessLicense). } \\
\text { Usage and distribution for commercial purposes as well as any dis- } \\
\text { tribution of modified material requires written permission. }\end{array}$
\end{tabular}

Kristin Marie Kvakkestad

Department of Medicine, Østfold Hospital, Kalnes PO Box 300

NO-1714 Grålum (Norway)

E-Mail kristinturcuta@gmail.com 
managed with a routine invasive compared to a conservative strategy [1-3]. Guidelines from the American Heart Association/American College of Cardiology and the European Society of Cardiology recommend a routine invasive strategy in patients with NSTEMI without age restrictions $[4,5]$. It is advised to consider benefits versus risks, including patient preferences, in older patients that are frail or have comorbid conditions with risk of adverse outcomes.

Elderly patients have been underrepresented in most RCTs performed, and outcome data in patients $\geq 75$ years with NSTEMI are limited. Results from 2 smaller RCTs of invasive management in elderly patients with NSTEMI differed regarding a benefit of a routine invasive strategy $[6,7]$. The larger after- 80 study [8], comparing an invasive versus a conservative strategy in 457 patients $\geq 80$ years, showed a $47 \%$ risk reduction for the primary endpoint (a composite of myocardial infarction [MI], urgent revascularization, stroke, or death) with the invasive strategy, but no significant difference in all-cause mortality [8]. In a large observational study including octogenarians with unstable angina or NSTEMI, an invasive strategy ( $\leq 48 \mathrm{~h}$ ) was associated with lower in-hospital mortality, but higher risk of cardiogenic shock [9]. Other observational studies have shown a favorable prognosis up to 1 year with an invasive strategy for elderly NSTEMI patients $[10,11]$, but long-term data are lacking. Due to the sparse data from clinical trials as well as from the realworld setting, the optimal management strategy for older patients with NSTEMI remains a subject of debate. The aim of the present study was to study short- and longterm survival in a cohort of NSTEMI patients $\geq 75$ years admitted to a cardiac center in Norway and managed with an invasive or a conservative strategy.

\section{Methods}

\section{Study Population}

This was an observational cohort study using data registered prospectively in the Oslo University Hospital (OUH) Ulleval MI registry. OUH Ulleval is a community hospital for 190,000 inhabitants and serves as a tertiary cardiac center for the region of Eastern Norway with a catchment population of $1,400,000$ people. From September 1, 2005, all consecutive patients with acute MI (AMI) admitted to our hospital were prospectively recorded in a local registry. The diagnosis of AMI was made according to the current AMI definition $[12,13]$, using troponin $\mathrm{T}$ as the cardiac biomarker. Classification of ST-segment elevation MI or NSTEMI was based on the diagnostic electrocardiogram [14]. The inclusion to our local registry closed on December 31,2011, due to the establishment of a national MI registry in Norway with a different owner.
In the present study, only the first admission for NSTEMI during the study period was included. The study population flow chart is presented in Figure 1. Patients aged $\geq 75$ years with NSTEMI were divided in 2 groups: (1) the invasive group defined as patients who underwent coronary angiography during the index hospitalization with percutaneous coronary intervention (PCI) or coronary artery bypass grafting (CABG) if indicated, in addition to recommended medical therapy and (2) the conservative group receiving recommended medical therapy only. Therapeutic decisions were solely at the discretion of the treating physician. Reasons for using an invasive or conservative strategy were not recorded in the registry.

\section{Data Collection, Definition of Variables, and Validation}

Data regarding baseline cardiovascular risk factors, treatment, invasive procedures, coronary angiograms, in-hospital complications, and in-hospital mortality were registered in an electronic database developed by the Mid-Norway Health Authority as described previously [14]. Variables were predefined in the OUH Ulleval MI registry user manual [15]. Coronary angiograms were described as normal if no visible atherosclerotic lesions, as nonobstructive coronary artery disease (CAD) if $<50 \%$ stenosis, or as significant CAD if $\geq 50 \%$ stenosis were present. One-vessel disease was defined as significant $\mathrm{CAD}$ in one vessel, and multiple vessel disease as the presence of significant CAD in $>1$ coronary arteries or in the left main coronary artery.

An internal validation procedure of the variables registered for 200 random patients was performed by the primary investigator. Values were compared with the patients' hospital records, and the estimated correlation between registry data and patient records was $>90 \%$. The continuous variable serum (s)-creatinine at admission had $10.6 \%$ missing values, and a sensitivity analysis was performed with normal (defined as $70 \mu \mathrm{mol} / \mathrm{L}$ ) or high (defined as 300 $\mu \mathrm{mol} / \mathrm{L}$ ) values replacing missing values. For all other included variables, missing values were $<5 \%$.

\section{Follow-Up and Outcomes}

Vital status until the end of follow-up on December 31, 2013, was obtained by linkage to the Norwegian Cause of Death registry. Follow-up time was defined as time from hospital admission to death or end of follow-up, whichever came first, and differed between patients due to the dynamic inclusion period. No information was available with respect to treatment after discharge from the index hospital admission.

Two primary analyses were performed. In the first, the primary endpoint was 30-day survival. In the second, the primary endpoint was survival during maximum 7 years of follow-up in patients being alive at day 30 after admission (a so-called landmark analysis) [16]. Secondary endpoints were OR for the association between an invasive strategy and 30-day mortality, and hazard ratio (HR) for mortality during follow-up among 30-day survivors in the invasive compared to the conservative group. In the landmark analysis of patients surviving the first 30 days, follow-up time was defined from day 30 to end of follow-up.

Ethics

The establishment of the local MI registry and the conduction of this study were approved by the Privacy Protection Officer at OUH. The Ministry of Health and Care Services approved exemption from the duty of confidentiality (November 16, 2011) and The
Kvakkestad et al. 
Fig. 1. Flow chart. * During index hospitalization. AMI, acute myocardial infarction; NSTEMI, non-ST-elevation myocardial infarction; STEMI, ST-elevation myocardial infarction.

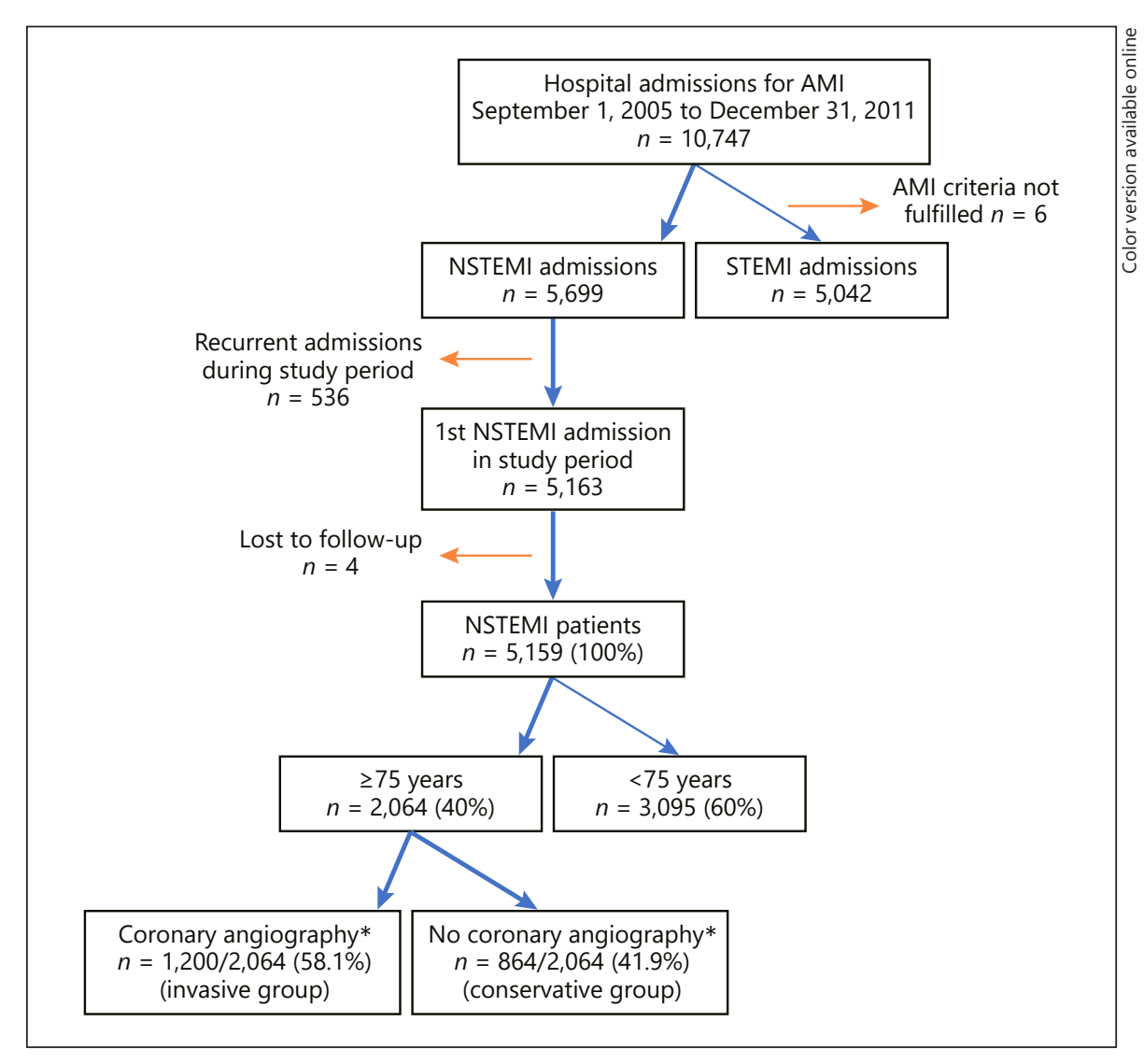

Norwegian Data Protection Authority provided concession for data linkage with the Norwegian Cause of Death Registry (January 5, 2012). All data were anonymized before analysis.

\section{Statistical Analysis}

Categorical variables are reported by numbers and percentage, after removing missing values (denominators may vary). Continuous variables are reported by mean \pm SD or median (25-75th percentile). Differences between the invasive and conservative groups in baseline risk factors and complications were tested with chisquare or Fisher exact tests for categorical variables and 2-sample $t$ test or Mann-Whitney $\mathrm{U}$ test for continuous variables, as appropriate. Survival from admission to day 30 and 7-year survival from day 30 were calculated with the life-table method and illustrated with the Kaplan-Meier survival function. Survival functions were compared with the log-rank test. Patients in the invasive group were considered as the exposed, while patients in the conservative group were the non-exposed. Logistic regression was used to calculate OR with $95 \%$ CI for the association between exposure and 30-day mortality. Based on previous knowledge [17-23] and clinical considerations, the following covariates were included to adjust for confounding: age, gender, previous hypertension, previous MI, previous revascularization, previous stroke, diabetes mellitus, peripheral artery disease, s-creatinine at admission, out-of-hospital resuscitation, heart failure, cardiogenic shock, atrial fibrillation/ -flutter, and antibiotic treatment. Cox regression was used to calculate HR with $95 \%$ CI for long-term mortality after 30 days in the exposed versus non-exposed. The proportional hazards assumption was evaluated using the log-log Kaplan-Meier plot. Confounding adjustment was as in the logistic regression. Pre-specified analyses for effect modification by age, gender and s-creatinine were performed by forcing an interaction term into the multivariate regression models, one at a time. As the primary analyses were significant, subgroup analysis of survival among patients in the invasive group treated with PCI, CABG or no revascularization was performed [24]. All tests were two-tailed, and a $p$ value $<0.05$ was considered significant. Analyses were performed with STATA 13 (Statacorp LP, TX, USA). The study confines with the STrengthening the Reporting of OBservational studies in Epidemiology checklist for reporting of observational studies [25].

\section{Results}

\section{Study Population}

Among 5,159 NSTEMI patients admitted to our hospital during 2005-2011, 2,064 patients (40.0\%) were $\geq 75$ years and constitute the study cohort (Fig. 1). The mean age was $82 \pm 5.5$ years and $48.2 \%$ were women. A total of 1,200 patients (58.1\%) underwent coronary angiography during the index hospitalization with PCI or CABG if 
Table 1. Baseline characteristics

\begin{tabular}{llcc}
\hline & \multicolumn{2}{l}{ NSTEMI patients $\geq 75$ years $(n=2,064)$} & $p$ value \\
\cline { 2 - 3 } & $\begin{array}{l}\text { invasive group } \\
(n=1,200)\end{array}$ & $\begin{array}{l}\text { conservative group } \\
(n=864)\end{array}$ & \\
\hline Age, mean \pm SD & $80.4 \pm 4.0$ & $86.4 \pm 5.3$ & $<0.0001$ \\
Women, $n(\%)$ & $473(39.4)$ & $521(60.3)$ & $<0.0001$ \\
Diabetes, $n(\%)$ & $248(20.7)$ & $164(19.0)$ & 0.343 \\
Hypertension, $n(\%)$ & $602(50.1)$ & $419(48.4)$ & 0.503 \\
Previous MI, $n(\%)$ & $396(33.0)$ & $300(34.8)$ & 0.401 \\
Previous revascularization, $n(\%)$ & $321(26.8)$ & $129(14.9)$ & $<0.0001$ \\
Previous stroke, $n$ (\%) & $165(13.8)$ & $203(23.6)$ & $<0.0001$ \\
Peripheral artery disease, $n(\%)$ & $127(10.6)$ & $75(8.7)$ & 0.154 \\
S-creatinine at admission, $\mu$ mol/L, median & & & $<0.0001$ \\
$\quad(25-75$ th percentile) & $87(72-107)$ & $99(76-132)$ & 0.863 \\
Out-of-hospital resuscitation, $n(\%)$ & $21(1.8)$ & $16(1.9)$ & \\
\hline
\end{tabular}

NSTEMI, non-ST-elevation myocardial infarction; MI, myocardial infarction; s-creatinine, serum-creatinine.

Table 2. Invasive procedures, in-hospital complications, and death

\begin{tabular}{|c|c|c|c|}
\hline & \multicolumn{2}{|c|}{ NSTEMI patients $\geq 75$ years $(n=2,064)$} & \multirow[t]{2}{*}{$p$ value } \\
\hline & $\begin{array}{l}\text { invasive group } \\
(n=1,200)\end{array}$ & $\begin{array}{l}\text { conservative group } \\
(n=864)\end{array}$ & \\
\hline Coronary angiography, $n(\%)$ & $1,200(100)$ & - & - \\
\hline PCI, $n(\%)$ & $580(48.3)$ & - & - \\
\hline $\mathrm{CABG}^{\mathrm{a}}, n(\%)$ & $126(10.5)$ & - & - \\
\hline $\begin{array}{l}\text { Symptom onset to angiography, days, median } \\
\text { (25-75th percentile) }\end{array}$ & $3(2-5)$ & - & - \\
\hline Normal vessels or nonobstructive CAD, $n(\%)$ & $131(11.0)$ & - & - \\
\hline One-vessel disease, $n(\%)$ & $449(37.8)$ & - & - \\
\hline Multiple vessel disease, $n(\%)$ & $608(51.2)$ & - & - \\
\hline Cardiogenic shock, $n(\%)$ & $15(1.3)$ & $15(1.7)$ & 0.363 \\
\hline Atrial fibrillation, $n(\%)$ & $62(5.2)$ & $136(15.7)$ & $<0.0001$ \\
\hline Heart failure, $n(\%)$ & $106(8.8)$ & $322(37.3)$ & $<0.0001$ \\
\hline Atrioventricular block $2-3^{\circ}, n(\%)$ & $14(1.2)$ & $11(1.3)$ & 0.827 \\
\hline In-hospital stroke, $n(\%)$ & $13(1.1)$ & $41(4.8)$ & $<0.0001$ \\
\hline Treatment with antibiotics, $n(\%)$ & $101(8.4)$ & $387(44.8)$ & $<0.0001$ \\
\hline VT/VF $>48 \mathrm{~h}$ from admission, $n(\%)$ & $11(0.9)$ & $5(0.6)$ & 0.388 \\
\hline Gastrointestinal bleeding, $n(\%)$ & $4(0.3)$ & $33(3.8)$ & $<0.0001$ \\
\hline In-hospital death, $n(\%)$ & $29(2.4)$ & $157(18.2)$ & $<0.0001$ \\
\hline
\end{tabular}

a CABG during index admission or planned for CABG later.

NSTEMI, non-ST-elevation myocardial infarction; PCI, percutaneous coronary intervention; CABG, coronary artery bypass grafting; CAD, coronary artery disease; VT, ventricular tachycardia; VF, ventricular fibrillation.

indicated (invasive group), and 864 patients (41.9\%) received recommended medical therapy only (conservative group). The median time from symptom onset to coronary angiography was 3 [2-5] days. Patients in the invasive group were younger, more likely to be men and previously revascularized, and less likely to have had a previous stroke and elevated s-creatinine at admission (Table 1). 
Table 3. 30 -Day and long-term survival* in NSTEMI patients $\geq 75$ years

\begin{tabular}{llr}
\hline & $\begin{array}{l}\text { Invasive group, } \\
(n=1,200), \%(95 \% \mathrm{CI})\end{array}$ & $\begin{array}{l}\text { Conservative group, } \\
(n=864), \%(95 \% \mathrm{CI})\end{array}$ \\
\hline 30-Day survival & $94.9(93.5-96.0)$ & $76.6(73.7-79.3)$ \\
\hline Landmark analysis: survival in patients & $(n=1,140)$ & $(n=665)$ \\
alive 30 days from admission & & \\
\hline 1 year & $90.8(89.0-92.3)$ & $66.8(63.1-70.2)$ \\
2 years & $84.3(82.0-86.3)$ & $53.2(49.4-56.9)$ \\
years & $78.0(75.4-80.3)$ & $38.8(35.0-42.5)$ \\
5 years & $70.9(67.9-73.6)$ & $28.5(24.9-32.2)$ \\
6 years & $62.1(58.7-65.3)$ & $20.3(16.8-24.0)$ \\
7 years & $52.9(48.9-56.7)$ & $15.5(12.1-19.2)$ \\
End of follow-up & $47.4(42.9-51.8)$ & $11.6(8.3-15.6)$ \\
\end{tabular}

* Life-table method.

Follow-up time from admission ( $n=2,064)$ : 1,011 days (25-75th percentile: $248-1,566)$.

NSTEMI, non-ST-elevation myocardial infarction.

Fig. 2. 30-day survival. Patients aged $\geq 75$ years with NSTEMI. Kaplan-Meier survival plot.

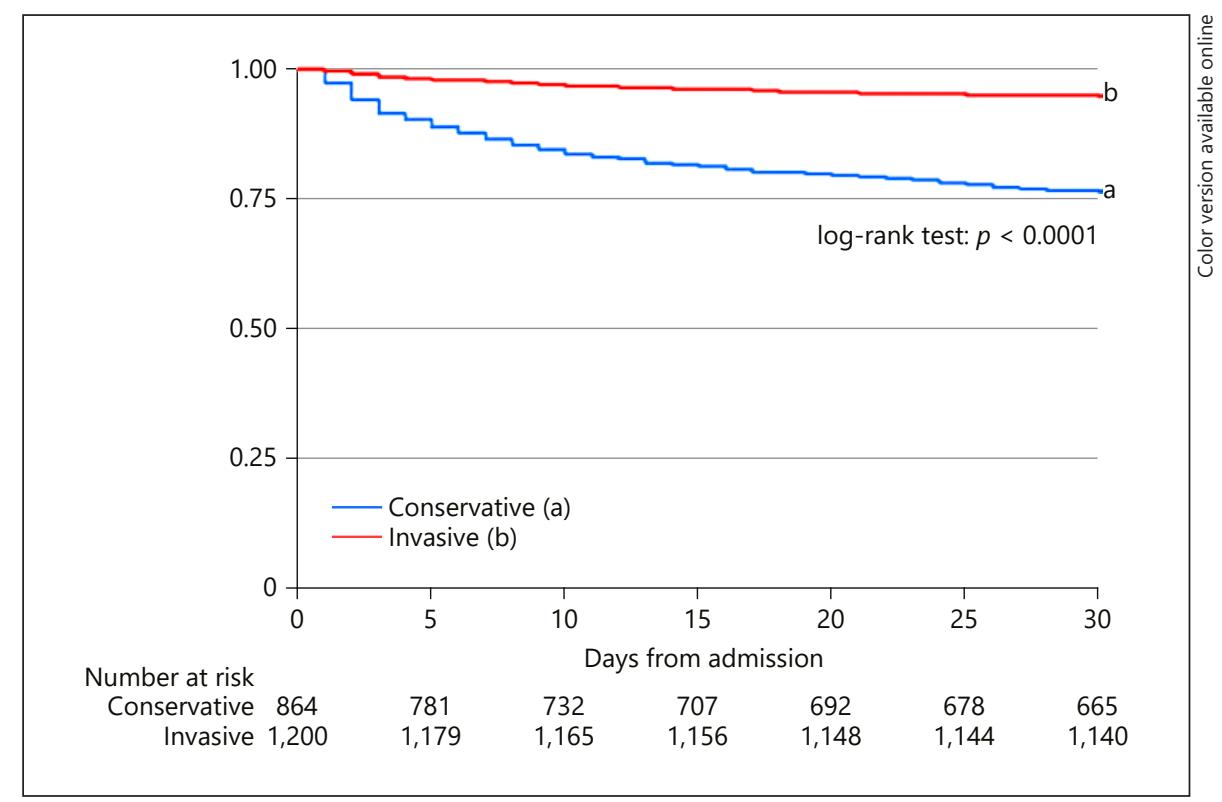

\section{Revascularization and In-Hospital Complications}

In the invasive group, 1,057 patients $(88.1 \%)$ had significant one- or multiple-vessel CAD, and 706 patients (58.8\%) were treated with PCI or CABG (Table 2). In the conservative group, by definition, no coronary angiography was performed during the index hospitalization. The proportion of patients with out-of-hospital resuscitation, cardiogenic shock, and in-hospital arrhythmias were similar in both groups (Tables 1,2). Compared to the conservative group, patients in the invasive group were less likely to have atrial fibrillation/flutter, heart failure, stroke, and antibiotic treatment during the hospital stay (Table 2).

\section{Outcomes}

During the first 30 days, 60/1,200 (5.0\%) of patients treated invasively died and 199/864 (23.0\%) in the conservative group (Table 3, Fig. 2). 
Fig. 3. Long-term survival. NSTEMI patients $\geq 75$ years alive at day 30 (Landmark analysis). Kaplan-Meier survival plot. Median follow-up 1,155 days (25-75th percentile: 634-1,687).

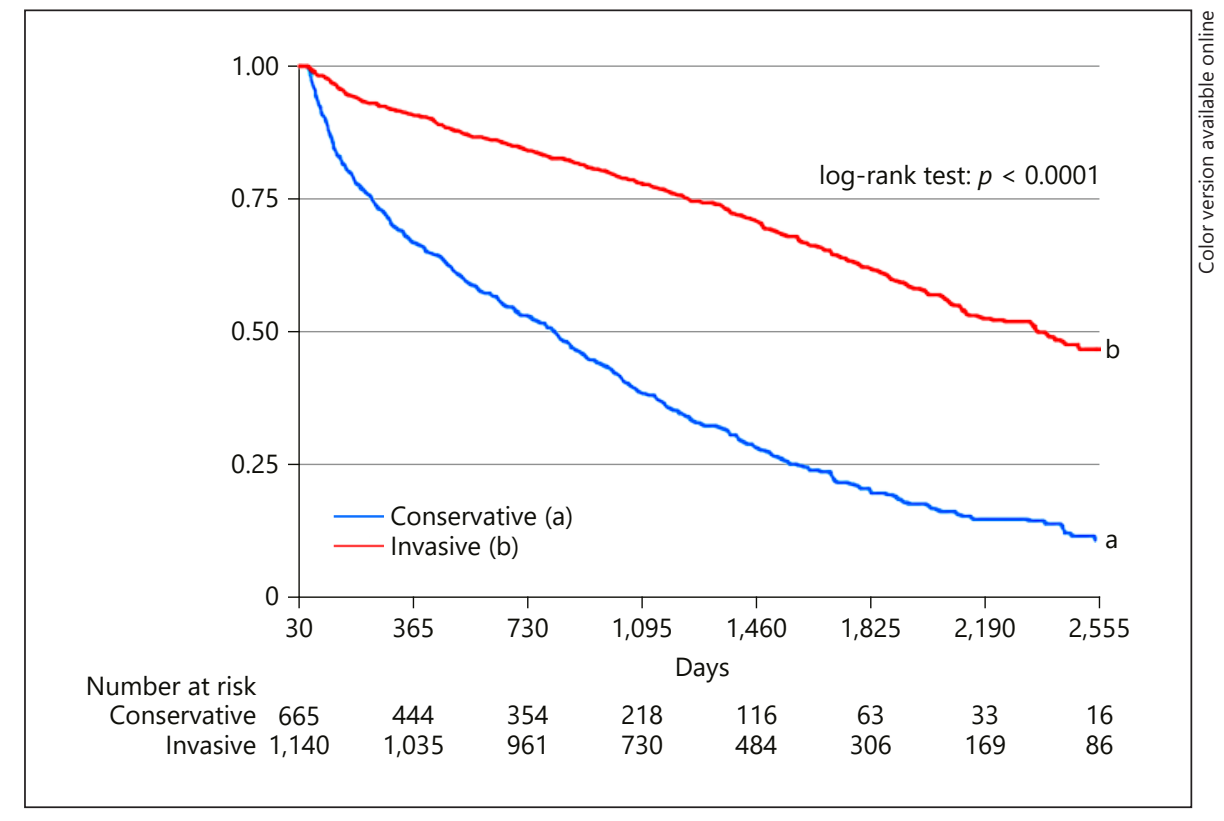

Table 4. Invasive strategy and mortality, NSTEMI patients $\geq 75$ years

\begin{tabular}{|c|c|c|}
\hline & OR $(95 \% \mathrm{CI})$ & $p$ value \\
\hline \multicolumn{3}{|c|}{ Association between an invasive strategy and 30-day mortality ${ }^{\mathrm{a}}$} \\
\hline Unadjusted & $0.18(0.13-0.24)$ & $<0.0001$ \\
\hline Age adjusted & $0.23(0.16-0.32)$ & $<0.0001$ \\
\hline Adjusted for baseline characteristics ${ }^{\mathrm{b}}$ & $0.31(0.21-0.45)$ & $<0.0001$ \\
\hline \multirow[t]{2}{*}{ Multivariate adjusted ${ }^{c}$} & $0.39(0.25-0.60)$ & $<0.0001$ \\
\hline & HR (95\% CI) & $p$ value \\
\hline \multicolumn{3}{|c|}{$\begin{array}{l}\text { Long-term mortality in the invasive versus the conservative group for } \\
\text { patients surviving the first } 30 \text { days }(n=1,805)^{\mathrm{d}}\end{array}$} \\
\hline Unadjusted & $0.29(0.26-0.33)$ & $<0.0001$ \\
\hline Age adjusted & $0.36(0.31-0.43)$ & $<0.0001$ \\
\hline Adjusted for baseline characteristics ${ }^{\mathrm{b}}$ & $0.40(0.33-0.47)$ & $<0.0001$ \\
\hline Multivariate adjusted $^{c}$ & $0.49(0.41-0.59)$ & $<0.0001$ \\
\hline
\end{tabular}

${ }^{a}$ Logistic regression.

b Adjustment for baseline characteristics: Age, female gender, s-creatinine, out-of-hospital resuscitation, previous hypertension, -myocardial infarction, -revascularisation or -stroke, diabetes mellitus, peripheral artery disease.

${ }^{c}$ Multivariate adjusted: adjustment for baseline characteristics + in-hospital atrial fibrillation/flutter, heart failure, cardiogenic shock, antibiotic treatment.

${ }^{\mathrm{d}}$ Cox regression with landmark at 30 days; median follow-up 1,155 days (25-75th percentile: 634-1,687).

NSTEMI, non-ST-elevation myocardial infarction; HR, hazard ratio.

Among patients who survived the first 30 days $(n=$ $1,805)$, median follow-up time was 1,155 days (6341,687 ), and maximum follow-up time was 2,974 days. Estimated 7 -year survival was $47.4 \%$ in the invasive group and $11.6 \%$ in the conservative group (Table 3 , Fig. 3). After multivariate adjustment, an invasive strategy was associated with $51 \%$ lower risk of death during follow-up compared to a conservative strategy (Table 4). 
Fig. 4. Actual revascularization. NSTEMI patients $\geq 75$ years managed with angiography only (a), angiography + PCI (b) or angiography + CABG (c). a 30-Day survival. Kaplan-Meier survival plot. b Long-term survival after 30 days. Kaplan-Meier survival plot. PCI, percutaneous coronary intervention; $\mathrm{CABG}$, coronary artery bypass grafting; revasc, revascularization. a

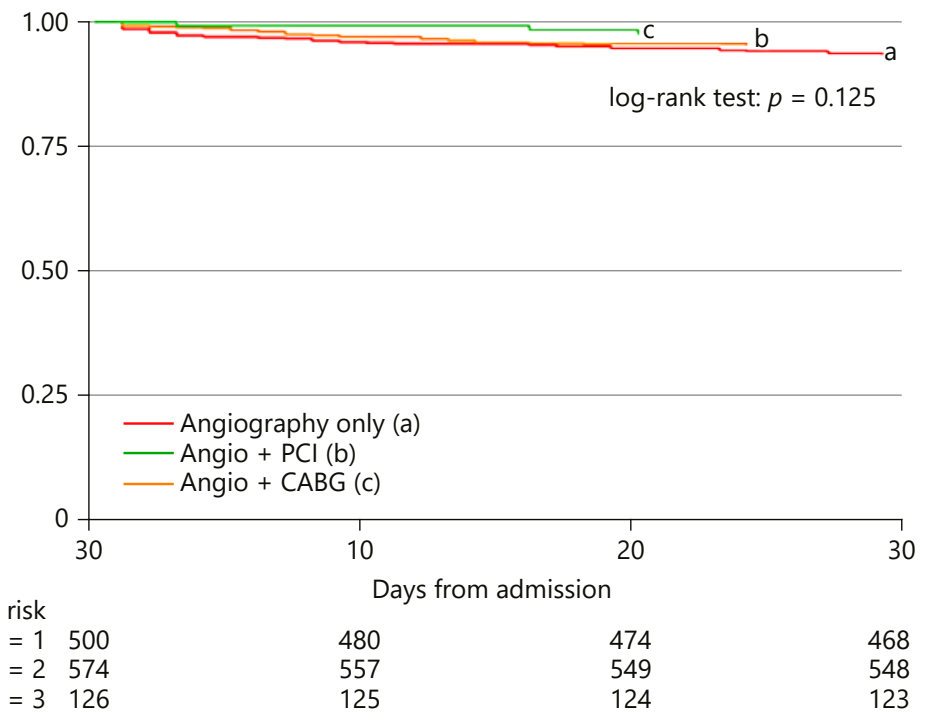

b

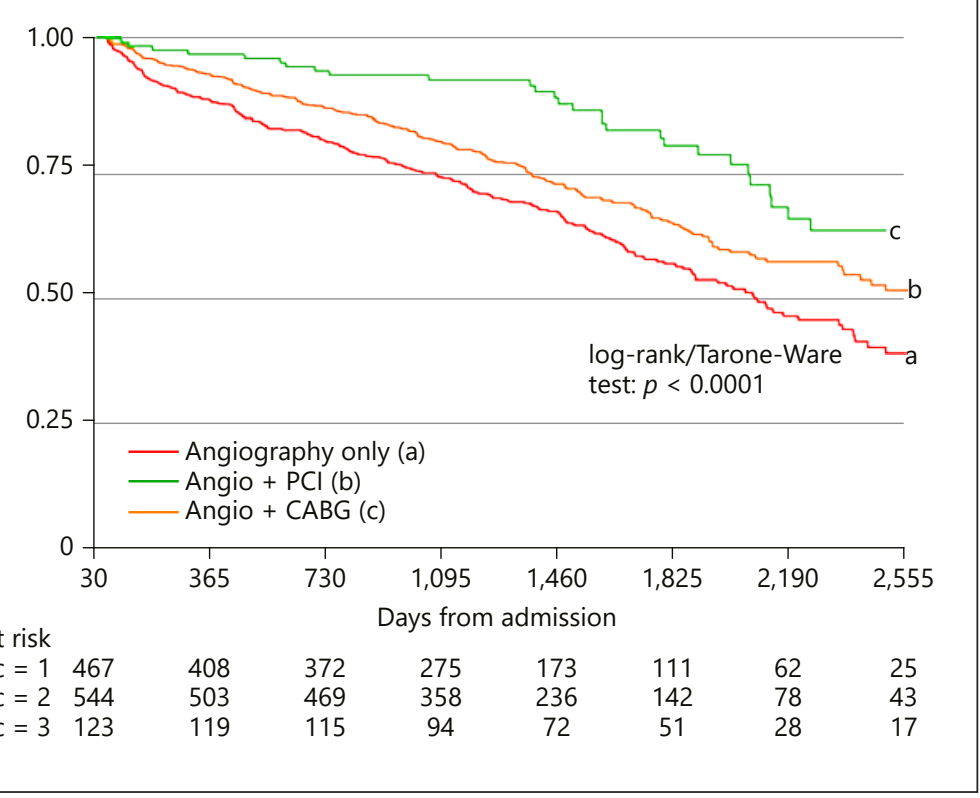

Number at risk Angio revasc $=1 \quad 500$ $\begin{array}{ll}\text { Angio revasc }=2 & 574 \\ \text { Angio revasc }=3 & 126\end{array}$
The proportional hazards assumption was considered valid.

There was effect modification by level of s-creatinine at admission on the association between an invasive strategy and long-term mortality ( $p$ interaction $=0.006$ ). When patients were dichotomized according to s-creatinine levels $(<110$ or $\geq 110 \mu \mathrm{mol} / \mathrm{L})$, the effect was larger for patients with s-creatinine $<110 \mu \mathrm{mol} / \mathrm{L}$ at admission (adjusted HR [aHR] 0.45 [95\% CI 0.38-0.54]) than for patients with s-creatinine $\geq 110 \mu \mathrm{mol} / \mathrm{L}$ (aHR 0.64 [95\% CI 0.47-0.87]). There was no significant effect modifica- tion by age $(p=0.166)$ or gender $(p=0.791)$. In a sensitivity analysis, there were no alteration of the association between s-creatinine and mortality in the Cox regression model. Therefore, we assumed that s-creatinine values were missing completely at random.

In a subgroup analysis of patients treated invasively, 30-day survival was similar for patients undergoing angiography only and for those revascularized with PCI or CABG ( $p=0.125$; Fig. 4a). Revascularization with PCI or CABG was not independently associated with 30 -day survival after adjustment for age and other baseline charac- 
teristics (adjusted $\mathrm{OR}_{\mathrm{PCI}} 0.77$ [95\% CI 0.41-1.43], adjusted $\mathrm{OR}_{\mathrm{CABG}} 0.48$ [95\% CI 0.12-1.96]).

After 30-days, estimated 7-year survival was $43.7 \%$ (95\% CI 37.2-50.1) for patients with angiography only $(n=467), 55.1 \%$ (95\% CI $49.0-60.8)$ with PCI $(n=544)$, and $67.5 \%$ (95\% CI 55.4-77.0) with CABG $(n=125$; Fig. 4b). After 30 days, actual revascularization with PCI or CABG was associated with lower risk of long-term mortality, also after multivariate adjustment $\left(\mathrm{aHR}_{\mathrm{PCI}} 0.73[95 \%\right.$ CI 0.59-0.90], $p=0.003$ and $\mathrm{aHR}_{\mathrm{CABG}} 0.43$ [95\% CI $0.28-$ $0.65], p<0.0001)$. The $\mathrm{PH}$-assumption was regarded valid.

\section{Discussion}

In this observational study of patients with NSTEMI aged $\geq 75$ years, the main findings were (1) 30-day survival was near $95 \%$, and 7 -year survival was almost $50 \%$, with the use of an invasive strategy. (2) Short- and longterm survival in the conservative group were lower, with a 30 -day survival of $77 \%$, and 7 -year survival of only $12 \%$. (3) Among invasively treated patients, revascularization with PCI or CABG was associated with improved longterm survival compared to angiography only.

To our knowledge, this is the first study to document survival exceeding 1 year for NSTEMI patients $\geq 75$ years treated with an invasive strategy. In line with our results, previous studies have reported in-hospital mortality ranging from 4 to $6 \%$ for invasively treated versus $7-11 \%$ for conservatively treated elderly patients with NSTEACS $[9,11]$. Among 1,936 NSTEMI patients $\geq 75$ years, 1 -year mortality was $10.7 \%$ for invasively versus $27.9 \%$ for conservatively treated [10]. In a pooled analysis from the FRISC-II, Conservative Treatment in Unstable Coronary Syndromes and RITA-3 (FIR) trials, 5-year cardiovascular mortality for elderly NSTE-ACS patients was only $18.5 \%$ [3]. The diverging results of mortality in observational cohorts and RCT's, suggest selection of healthier, lower-risk patients for RCTs than in real-life clinical practice. The problem in the present study was a selection of patients considered for an invasive strategy, both in community hospitals and in the tertiary center. Selection bias can result in overestimation of survival rates or the effect of an intervention. Since this was a registry based on clinical practice, the therapeutic strategy was at the physician's discretion, and no specific exclusion criteria were applied for invasive treatment. The lack of specific criteria for therapeutic strategy might limit the external validity and generalizability of our results. Furthermore, patients in our study were treated in 2005-
2011, before wide use of 2 nd generation drug-eluting stents, newer antiplatelet agents and catheterization techniques and survival rates may not be generalizable to all elderly NSTEMI patients.

Although RCTs are the gold standard for evaluating the effect of interventions, including elderly patients in clinical trials may be difficult, and RCTs of invasive treatment in elderly patients have been terminated prematurely due to slow recruitment [26]. Therefore, results from observational studies with high internal validity can provide important knowledge reflecting clinical practice for elderly patients underrepresented or excluded from clinical trials [27].

As expected, patients treated invasively in our study were younger (mean age 80.4 vs. 86.4 years). They were more likely men and had a higher percentage previous revascularization, but less often had a previous stroke. These factors are associated with risk of CAD and adverse outcomes in the setting of ACS $[28,29]$. Other known prognostic factors, such as bleeding history or anaemia [29], were not registered in this study, but may have influenced the treatment decision and outcomes in this elderly cohort. Diabetes, hypertension, and peripheral artery disease were similar for patients treated invasively or conservatively [30]. The fact that higher risk elderly AMI patients are not treated invasively is described as the "age-risk paradox" [31], that is, the advantage of PCI increases with background risk, but that increased background risk results in a patient not being revascularized. Complicating observational studies of elderly patients, it may be the presence of contraindications to coronary angiography or PCI (and thus another disease), that account for the increased mortality risk, and not the conservative strategy itself [32]. Comorbidities such as cancer, liver disease, dementia, or chronic obstructive pulmonary disease and life expectancy should be considered [4] in the choice of treatment strategy. Previous studies of elderly patients with AMI or NSTEACS have reported lower prevalence of comorbidities among invasively compared to conservatively treated (chronic obstructive pulmonary disease $10-18$ vs. 13-26\%, cancer 6 vs. $12 \%$, and dementia 5 vs. $18 \%$, respectively) [9, 33]. Frailty can be defined as an age-related vulnerability to a stressor event, increasing the risk of adverse outcomes [34]. Mortality risk is increased among frail compared to non-frail elderly AMI patients, independent of chronological age and clinical risk scores [35-38]. Unfortunately, these factors were not registered in the present study and could therefore not be adjusted for in the risk estimates.

Patients treated invasively had lower levels of s-creatinine at admission compared to patients treated conser-
86

Cardiology 2019;144:79-89 DOI: $10.1159 / 000503442$
Kvakkestad et al. 
vatively. Our finding of effect modification by level of s-creatinine suggests the invasive strategy to be less effective in elderly NSTEMI patients with renal dysfunction. This corresponds to findings that moderate to severe renal dysfunction is associated with mortality among invasively treated AMI patients [20]. There is a need for more knowledge about the influence of an invasive strategy in elderly NSTEMI patients with renal dysfunction.

The association between actual revascularization with PCI or CABG and improved long-term survival may be less influenced by selection bias. Reasons for not performing PCI or CABG were unfortunately not registered in our study, and factors such as non-obstructive coronary lesions, unsuitable coronary anatomy, technical difficulties, or per-procedural complications may have influenced long-term survival. In line with our results, a per-protocol analysis from the Invasive versus Conservative Treatment in Unstable Coronary Syndromes trial [39] found that actual revascularization was associated with reduced 4-year mortality among NSTE-ACS patients, as opposed to the original intention-to-treat analysis that was neutral [24].

Our study describes better survival for elderly NSTEMI patients clinically selected for an invasive strategy compared to conservative strategy. However, the study was not designed for determining a treatment effect, and selection bias and confounding factors may account for the observed difference in risk and survival between groups. Patients that were revascularized had a better long-term prognosis. The proportion of elderly patients treated with an invasive strategy was quite low (only $48 \%$ ), as in previous studies of elderly NSTE-ACS patients [9-11]. However, a total of 59\% of NSTEMI patients $\geq 75$ years treated with an invasive strategy were revascularized. For comparison, $67 \%$ of invasively treated in the total cohort of NSTEMI patients during 2005-2011 from our center (all ages) received actual revascularization [40]. One can speculate that more elderly NSTEMI patients could benefit from an invasive strategy with revascularization. With the higher life expectancy and growth of the elderly population, an evidence-based strategy on how to treat elderly patients with NSTEMI is essential [8]. Adequately powered RCTs for mortality after an invasive versus conservative strategy in elderly AMI patients are wanted. Awaiting this, more descriptive studies are needed of prognostic factors both for treatment decisions and long-term survival to better anticipate the best treatment for complex, high-risk individuals, often found among elderly patients.

Invasive or Conservative Strategy in Elderly NSTEMI Patients

\section{Strengths and Limitations}

The strengths of our study are long-term survival estimates for a large, consecutive NSTEMI cohort $\geq 75$ years reflecting clinical practice. The subgroup analysis of actual revascularization differentiates between patients selected for an invasive strategy based on clinical features and shows a strong association between treatment and long-term survival for elderly NSTEMI patients. The landmark analysis of survival after 30 days was performed to reduce immortal time bias [41], that is, bias due to acute illness severity with death before coronary angiography could be performed.

The main limitation of our study was the observational design with a physician selection of patients for invasive or conservative strategy. The treatment decision was not registered. Unmeasured confounding may have influenced the treatment strategy and survival. Heart rate, blood pressure, left ventricular ejection fraction, medications after discharge, and compliance were not registered. With the emergence of high-sensitivity cardiac troponin assays and increasing awareness that reference values may be different for women and men, diagnostic sensitivity for NSTEMI may have changed since the study period [42]. In the future, characteristics of clinical NSTEMI cohorts may potentially alter due to enhanced diagnostic accuracy and risk stratification by added biomarkers, that is, growth differentiation factor-15, natriuretic peptides, copeptin, or heart-type fatty acid-binding protein [4345].

Revascularization or cardiac rehabilitation during follow-up may have influenced long-term survival. Noncardiovascular causes of death may influence long-term survival [40], especially in elderly cohorts. End points such as burden of symptoms, hospital readmissions, or quality of life during long-term follow-up are all important outcomes, which should be included in future studies.

This study was conducted in a university hospital, being a combination of a community hospital and a tertiary cardiac center, and the results are not necessarily generalizable to all elderly NSTEMI patients. Despite our efforts to convey bias by prospective registration, landmark analysis, and controlling for confounders, a causal effect of an invasive strategy on survival in elderly NSTEMI patients cannot be inferred. 


\section{Conclusion}

In this real-life cohort of NSTEMI patients $\geq 75$ years, 30 -day survival was $95 \%$, and 7 -year survival was $47 \%$ with an invasive strategy. Revascularized patients had a superior long-term prognosis. Short- and long-term survival with a conservative strategy was significantly lower, probably due to selection bias and unmeasured confounding.

\section{Acknowledgments}

The authors wish to thank the physicians at the Department of Cardiology, OUH Ulleval, for data collection, the Mid-Norway Regional Health Authority for supplying the electronic database, and the Norwegian Cause of Death registry for mortality data.

\section{Disclosure Statement}

The authors have no conflicts of interest to disclose.

\section{Funding Source}

Funded by grant number 2013028 from the Scientific Board of the South-Eastern Norway Regional Health Authority, Hamar, Norway.

\section{Author Contributions}

K.M.K.: has contributed in study design, validation, analysis and interpretation of results, drafting of the paper, tables and figures, and writing of the final document. J.M.G.: has contributed in study design, analysis and interpretation of results, and writing of the final document. J.E. and G.O.A. have contributed in data collection, study design, analysis and interpretation of results, and writing of the final document. E.F. have contributed in study design, analysis and interpretation of results, and writing of the final document. C.H.H. have contributed in data collection, validation and writing of the final document. S.H. had the MI registry idea, contributed in study design, validation, analysis and interpretation of results, drafting of the paper and tables, and writing of the final document. All authors have approved the final version for publication.

\section{References}

1 Lagerqvist B, Husted S, Kontny F, Ståhle E, Swahn E, Wallentin L; Fast Revascularisation during InStability in Coronary artery disease (FRISC-II) Investigators. 5-year outcomes in the FRISC-II randomised trial of an invasive versus a non-invasive strategy in non-ST-elevation acute coronary syndrome: a follow-up study. Lancet. 2006 Sep;368(9540):998-1004.

2 Fox KA, Clayton TC, Damman P, Pocock SJ, de Winter RJ, Tijssen JG, et al.; FIR Collaboration. Long-term outcome of a routine versus selective invasive strategy in patients with non-STsegment elevation acute coronary syndrome a meta-analysis of individual patient data. J Am Coll Cardiol. 2010 Jun;55(22):2435-45.

3 Damman P, Clayton T, Wallentin L, Lagerqvist B, Fox KA, Hirsch A, et al. Effects of age on long-term outcomes after a routine invasive or selective invasive strategy in patients presenting with non-ST segment elevation acute coronary syndromes: a collaborative analysis of individual data from the FRISC II - ICTUS - RITA-3 (FIR) trials. Heart. 2012 Feb;98(3):207-13.

4 Roffi M, Patrono C, Collet JP, Mueller C, Valgimigli M, Andreotti F, et al.; ESC Scientific Document Group. 2015 ESC Guidelines for the management of acute coronary syndromes in patients presenting without persistent ST-segment elevation: Task Force for the Management of Acute Coronary Syndromes in Patients Presenting without Persistent STSegment Elevation of the European Society of Cardiology (ESC). Eur Heart J. 2016 Jan; 37(3):267-315.
5 Amsterdam EA, Wenger NK, Brindis RG, Casey DE Jr, Ganiats TG, Holmes DR Jr, et al.; ACC/AHA Task Force Members; Society for Cardiovascular Angiography and Interventions and the Society of Thoracic Surgeons. 2014 AHA/ACC guideline for the management of patients with non-ST-elevation acute coronary syndromes: executive summary: a report of the American College of Cardiology/American Heart Association Task Force on Practice Guidelines. Circulation. 2014 Dec;130(25):2354-94.

6 Bach RG, Cannon CP, Weintraub WS, DiBattiste PM, Demopoulos LA, Anderson HV, et al. The effect of routine, early invasive management on outcome for elderly patients with non-ST-segment elevation acute coronary syndromes. Ann Intern Med. 2004 Aug; 141(3):186-95.

7 Savonitto S, Cavallini C, Petronio AS, Murena E, Antonicelli R, Sacco A, et al.; Italian Elderly ACS Trial Investigators. Early aggressive versus initially conservative treatment in elderly patients with non-ST-segment elevation acute coronary syndrome: a randomized controlled trial. JACC Cardiovasc Interv. 2012 Sep;5(9):906-16.

8 Tegn N, Abdelnoor M, Aaberge L, Endresen K, Smith P, Aakhus S, et al.; After Eighty study investigators. Invasive versus conservative strategy in patients aged 80 years or older with non-ST-elevation myocardial infarction or unstable angina pectoris (After Eighty study): an open-label randomised controlled trial. Lancet. 2016 Mar;387(10023):1057-65.
9 Kolte D, Khera S, Palaniswamy C, Mujib M, Fonarow GC, Ahmed A, et al. Early invasive versus initial conservative treatment strategies in octogenarians with UA/NSTEMI. Am J Med. 2013 Dec;126(12):1076-83.e1.

10 Bauer T, Koeth O, Jünger C, Heer T, Wienbergen H, Gitt A, et al.; Acute Coronary Syndromes Registry (ACOS) Investigators. Effect of an invasive strategy on in-hospital outcome in elderly patients with non-ST-elevation myocardial infarction. Eur Heart J. 2007 Dec; 28(23):2873-8.

11 Devlin G, Gore JM, Elliott J, Wijesinghe N, Eagle KA, Avezum A, et al.; GRACE Investigators. Management and 6-month outcomes in elderly and very elderly patients with highrisk non-ST-elevation acute coronary syndromes: The Global Registry of Acute Coronary Events. Eur Heart J. 2008 May;29(10): 1275-82.

12 Alpert JS, Thygesen K, Antman E, Bassand JP. Myocardial infarction redefined-a consensus document of The Joint European Society of Cardiology/American College of Cardiology Committee for the redefinition of myocardial infarction. J Am Coll Cardiol. 2000 Sep;36(3):959-69.

13 Thygesen K, Alpert JS, White HD, Jaffe AS, Apple FS, Galvani M, et al.; Joint ESC/ACCF/ AHA/WHF Task Force for the Redefinition of Myocardial Infarction. Universal definition of myocardial infarction. Eur Heart J. 2007 Oct;28(20):2525-38. 
14 Kvakkestad KM, Abdelnoor M, Claussen PA, Eritsland J, Fossum E, Halvorsen S. Longterm survival in octogenarians and older patients with ST-elevation myocardial infarction in the era of primary angioplasty: A prospective cohort study. Eur Heart J Acute Cardiovasc Care. 2016 Jun;5(3):243-52.

15 Claussen PA, Abdelnoor M, Kvakkestad KM, Eritsland J, Halvorsen S. Prevalence of risk factors at presentation and early mortality in patients aged 80 years or older with ST-segment elevation myocardial infarction. Vasc Health Risk Manag. 2014 Dec;10:683-9.

16 van Houwelingen HC. Dynamic Prediction by Landmarking in Event History Analysis. Scand J Stat. 2007;34(1):70-85.

17 Bagnall AJ, Goodman SG, Fox KA, Yan RT, Gore JM, Cheema AN, et al.; Canadian Acute Coronary Syndrome Registry I and II Investigators; Canadian Global Registry of Acute Coronary Events (GRACE/GRACE2) Investigators. Influence of age on use of cardiac catheterization and associated outcomes in patients with non-ST-elevation acute coronary syndromes. Am J Cardiol. 2009 Jun; 103(11):1530-6.

18 Milcent C, Dormont B, Durand-Zaleski I, Steg PG. Gender differences in hospital mortality and use of percutaneous coronary intervention in acute myocardial infarction: microsimulation analysis of the 1999 nationwide French hospitals database. Circulation. 2007 Feb;115(7):833-9.

19 DeGeare VS, Stone GW, Grines L, Brodie BR, Cox DA, Garcia E, et al. Angiographic and clinical characteristics associated with increased in-hospital mortality in elderly patients with acute myocardial infarction undergoing percutaneous intervention (a pooled analysis of the primary angioplasty in myocardial infarction trials). Am J Cardiol. 2000 Jul;86(1):30-4.

20 Sabroe JE, Thayssen P, Antonsen L, Hougaard $\mathrm{M}$, Hansen $\mathrm{KN}$, Jensen LO. Impact of renal insufficiency on mortality in patients with ST-segment elevation myocardial infarction treated with primary percutaneous coronary intervention. BMC Cardiovasc Disord. $2014 \mathrm{Feb} ; 14(1): 15$.

21 Kvakkestad KM, Sandvik L, Andersen GO, Sunde K, Halvorsen S. Long-term survival in patients with acute myocardial infarction and out-of-hospital cardiac arrest: A prospective cohort study. Resuscitation. 2018 Jan;122:417.

22 Carnendran L, Abboud R, Sleeper LA, Gurunathan R, Webb JG, Menon V, et al. Trends in cardiogenic shock: report from the SHOCK Study. The SHould we emergently revascularize Occluded Coronaries for cardiogenic shocK? Eur Heart J. 2001 Mar;22(6):472-8.

23 Wu AH, Parsons L, Every NR, Bates ER; Second National Registry of Myocardial Infarction. Hospital outcomes in patients presenting with congestive heart failure complicating acute myocardial infarction: a report from the Second National Registry of Myocardial In- farction (NRMI-2). J Am Coll Cardiol. 2002 Oct;40(8):1389-94.

24 Hirsch A, Windhausen F, Tijssen JG, Oude Ophuis AJ, van der Giessen WJ, van der Zee PM, et al.; Invasive versus Conservative Treatment in Unstable coronary Syndromes Investigators. Diverging associations of an intended early invasive strategy compared with actual revascularization, and outcome in patients with non-ST-segment elevation acute coronary syndrome: the problem of treatment selection bias. Eur Heart J. 2009 Mar; 30(6):645-54.

25 STROBE statement-checklist of items that should be included in reports of observational studies (STROBE initiative). Int J Public Health. 2008;53(1):3-4.

26 Bueno H, Betriu A, Heras M, Alonso JJ, Cequier A, García EJ, et al.; TRIANA Investigators. Primary angioplasty vs. fibrinolysis in very old patients with acute myocardial infarction: TRIANA (TRatamiento del Infarto Agudo de miocardio eN Ancianos) randomized trial and pooled analysis with previous studies. Eur Heart J. 2011 Jan;32(1):51-60.

27 Sørensen HT, Lash TL, Rothman KJ. Beyond randomized controlled trials: a critical comparison of trials with nonrandomized studies. Hepatology. 2006 Nov;44(5):1075-82.

28 Six AJ, Backus BE, Kelder JC. Chest pain in the emergency room: value of the HEART score. Neth Heart J. 2008 Jun;16(6):191-6.

29 Moscucci M, Fox KA, Cannon CP, Klein W, López-Sendón J, Montalescot G, et al. Predictors of major bleeding in acute coronary syndromes: the Global Registry of Acute Coronary Events (GRACE). Eur Heart J. 2003 Oct; 24(20):1815-23.

30 Fox KA, Carruthers KF, Dunbar DR, Graham C, Manning JR, De Raedt H, et al. Underestimated and under-recognized: the late consequences of acute coronary syndrome (GRACE UK-Belgian Study). Eur Heart J. 2010 Nov; 31(22):2755-64.

31 Di Bari M, Balzi D, Fracchia S, Barchielli A, Orso F, Sori A, et al.; Acute Myocardial Infarction in Florence 2 (AMI Florence-2) Working Group. Decreased usage and increased effectiveness of percutaneous coronary intervention in complex older patients with acute coronary syndromes. Heart. 2014 Oct;100(19):1537-42.

32 Gottlieb S, Boyko V, Harpaz D, Hod H, Cohen M, Mandelzweig L, et al.; Israeli Thrombolytic Survey Group. Long-term (threeyear) prognosis of patients treated with reperfusion or conservatively after acute myocardial infarction. J Am Coll Cardiol. 1999 Jul;34(1):70-82.

33 Libungan B, Karlsson T, Albertsson P, Herlitz J. Elderly patients with myocardial infarction selected for conservative or invasive treatment strategy. Clin Interv Aging. 2015 Jan; 10: 321-7.

34 Clegg A, Young J, Iliffe S, Rikkert MO, Rockwood K. Frailty in elderly people. Lancet. 2013 Mar;381(9868):752-62.
35 Ekerstad N, Swahn E, Janzon M, Alfredsson J, Löfmark R, Lindenberger M, et al. Frailty is independently associated with 1-year mortality for elderly patients with non-ST-segment elevation myocardial infarction. Eur J Prev Cardiol. 2014 Oct;21(10):1216-24.

36 Sanchis J, Bonanad C, Ruiz V, Fernández J, García-Blas S, Mainar L, et al. Frailty and other geriatric conditions for risk stratification of older patients with acute coronary syndrome. Am Heart J. 2014 Nov;168(5):784-91.

37 Pogorevici A, Citu IM, Bordejevic DA, Caruntu F, Tomescu MC. Canada acute coronary syndrome score was a stronger baseline predictor than age $\geq 75$ years of in-hospital mortality in acute coronary syndrome patients in western Romania. Clin Interv Aging. 2016 Apr;11:481-8.

38 White HD, Westerhout CM, Alexander KP Roe MT, Winters KJ, Cyr DD, et al.; TRILOGY ACS investigators. Frailty is associated with worse outcomes in non-ST-segment elevation acute coronary syndromes: insights from the TaRgeted platelet Inhibition to cLarify the Optimal strateGy to medicallY manage Acute Coronary Syndromes (TRILOGY ACS) trial. Eur Heart J Acute Cardiovasc Care. 2016 Jun;5(3):231-42.

39 Hirsch A, Windhausen F, Tijssen JG, Verheugt FW, Cornel JH, de Winter RJ; Invasive versus Conservative Treatment in Unstable coronary Syndromes (ICTUS) investigators. Long-term outcome after an early invasive versus selective invasive treatment strategy in patients with non-ST-elevation acute coronary syndrome and elevated cardiac troponin T (the ICTUS trial): a followup study. Lancet. 2007 Mar;369(9564):82735.

40 Kvakkestad KM, Wang Fagerland M, Eritsland J, Halvorsen S. Gender differences in all-cause, cardiovascular and cancer mortality during long-term follow-up after acute myocardial infarction; a prospective cohort study. BMC Cardiovasc Disord. 2017 Mar; 17(1):75.

41 Suissa S. Immortal time bias in pharmacoepidemiology. Am J Epidemiol. 2008 Feb; 167(4):492-9.

42 Shah AS, McAllister DA, Mills R, Lee KK, Churchhouse AM, Fleming KM, et al. Sensitive troponin assay and the classification of myocardial infarction. Am J Med. 2015 May; 128(5):493-501.e3.

43 Mueller C. Biomarkers and acute coronary syndromes: an update. Eur Heart J. 2014 Mar; 35(9):552-6.

44 Wang J, Wei L, Yang X, Zhong J. Roles of Growth Differentiation Factor 15 in Atherosclerosis and Coronary Artery Disease. J Am Heart Assoc. 2019 Sep;8(17):e012826.

45 Mueller C, Möckel M, Giannitsis E, Huber K, Mair J, Plebani M, et al.; ESC Study Group on Biomarkers in Cardiology of the Acute Cardiovascular Care Association. Use of copeptin for rapid rule-out of acute myocardial infarction. Eur Heart J Acute Cardiovasc Care. 2018 Sep;7(6):570-6. 